\title{
Reduction of eco-toxicity risk of heavy metals in the rotary drum composting of water hyacinth: Waste lime application and mechanisms
}

\author{
Jiwan Singh ${ }^{1}$, Ajay S. Kalamdhad ${ }^{2}$, Byeong-Kyu Lee $^{3^{\dagger}}$ \\ ${ }^{1}$ Department of Environmental Engineering, Kwangwoon University, Seoul 139-701, Republic of Korea \\ ${ }^{2}$ Department of Civil Engineering, Indian Institute of Technology Guwahati, Assam 781039, India \\ ${ }^{3}$ Department of Civil and Environmental Engineering, University of Ulsan, Ulsan 680-749, Republic of Korea
}

\begin{abstract}
Experiments were conducted on the immobilization of eight heavy metals ( $\mathrm{HMs})(\mathrm{Zn}, \mathrm{Cu}, \mathrm{Mn}, \mathrm{Fe}, \mathrm{Ni}, \mathrm{Pb}, \mathrm{Cd}$, and $\mathrm{Cr}$ ) during 20 -day rotary drum composting of water hyacinth. The Tessier sequential extraction procedure was used to investigate the fractionation of HMs. The eco-toxicity risk of HMs was assessed by risk assessment code (RAC). In the results, the bioavailability factor (BAF) for different HMs presented in the following order: $\mathrm{Mn}>\mathrm{Zn}=\mathrm{Fe}>\mathrm{Cu}>\mathrm{Cr}>\mathrm{Cd}=\mathrm{Pb}>\mathrm{Ni}$. The total concentration of $\mathrm{Pb}$ was higher than that of $\mathrm{Zn}, \mathrm{Cu}, \mathrm{Mn}, \mathrm{Cd}$ and $\mathrm{Cr}$; however, its BAF was the lowest among these HMs. These results confirmed that the eco-toxicity of HMs depends on bioavailable fractions rather than on the total concentration. The greatest reduction in bioavailability and eco-toxicity risk of $\mathrm{HMs}$ occurred in lime $1 \%$ and $2 \%$ as compared to control and lime $3 \%$. The eco-toxicity risk of $\mathrm{Fe}, \mathrm{Ni}, \mathrm{Pb}, \mathrm{Cd}$ and $\mathrm{Cr}$ was reduced from low risk to zero risk by rotary drum composting. These studies demonstrated the high efficiency of the rotary drum for degrading compost materials and for reducing the bioavailability and eco-toxicity risk of HMs during the composting process.
\end{abstract}

Keywords: ANOVA, Composting, Fractionation, HMs, RAC, Waste lime

\section{Introduction}

Rotary drum composting is a well-organized, decentralized and encouraging technique for converting bio waste into compost due to proper agitation, aeration and mixing of the compost materials. In addition, consistent and homogeneous compost materials are generated during the process [1]. Certain conditions developed inside the reactor such as warm and moist environment with abundant amounts of oxygen and organic material available in the composting mixture facilitate the strong growth of aerobic microbes that decompose waste more rapidly. Therefore, rotary drum has proven successful for reducing composting time, producing high quality compost and reducing the bioavailability of heavy metals (HMs), as compared to the agitated pile composting.

Water hyacinth (Eichhornia crassipes) has been used widely for treating heavily polluted wastewaters due to its capacity for HM accumulation, but the economic disposal of water hyacinths used after wastewater treatment remains a problem [2]. Composting in rotary drums is a highly promising technique for converting biomass into well stabilized organic matter [1]. A high HM content in the final compost and vermicompost of water hyacinth is the major limitation in improving soil quality, and hence plant and human health [3, 4]. The application of such compost to agricultural fields is problematic due to the ease of transfer of HMs from compost to soil, to plant and then to humans. The bioavailability of HMs to plants depends on their different fractions or ways of binding, rather than on their total concentrations [5].

Lime is a common amendment material for enhancing the composting process and reducing the bioavailability of HMs to plants [6]. In India, about 0.75 million tonnes of lime sludge are generated per year during acetylene production [7]. The present study investigated the combined effects of waste lime in rotary drum composting in the immobilization of HMs. Very limited research is available on speciation of HMs during water hyacinth composting in agitated pile [8], rotary drum [3] and agitated pile with waste lime [9]. Furthermore, no information is available on the fractionation and reduction of eco-toxicity risk of HMs in the rotary drum composting of water hyacinths with waste lime. Therefore, the study objectives 
were to reduce the bioavailability and eco-toxicity risk of eight HMs ( $\mathrm{Zn}, \mathrm{Cu}, \mathrm{Mn}, \mathrm{Fe}, \mathrm{Ni}, \mathrm{Pb}, \mathrm{Cd}$ and $\mathrm{Cr}$ ) in the rotary drum composting of water hyacinth with lime application, and to determine the mechanism for the immobilization of HMs.

\section{Materials and Methods}

\subsection{Feedstock Materials}

Water hyacinths were collected from the Amingoan industrial area near the Indian Institute of Technology Guwahati (IITG), India. Cattle manure was obtained from a dairy farm, and sawdust was collected from a saw mill near the IITG campus. Waste lime was collected from Assam Air Products, Guwahati, India. The collected lime dried in an oven at $105^{\circ} \mathrm{C}$ for $24 \mathrm{~h}$, ground using an electrical grinder and sieved through $0.22 \mathrm{~mm}$ sieves. The initial characteristics of waste lime have already been reported elsewhere [9]. Before starting the composting process, the particle size of the compost material was restricted to $1 \mathrm{~cm}$, which is useful for good aeration and moisture control. Fig. 1 presents a schematic view of the rotary drum composting process, preparation of compost materials and collection of raw materials. The waste compositions in different treatments were as follows:

Control: Water hyacinth (90 kg) + cattle manure (45 kg) + sawdust $(15 \mathrm{~kg})$

Lime 1: Water hyacinth $(90 \mathrm{~kg})+$ cattle manure $(45 \mathrm{~kg})$ + sawdust $(15 \mathrm{~kg})+1 \%$ waste lime

Lime 2: Water hyacinth (90 kg) + cattle manure (45 kg) + sawdust $(15 \mathrm{~kg})+2 \%$ waste lime

Lime 3: Water hyacinth $(90 \mathrm{~kg})+$ cattle manure $(45 \mathrm{~kg})$ + sawdust $(15 \mathrm{~kg})+3 \%$ waste lime

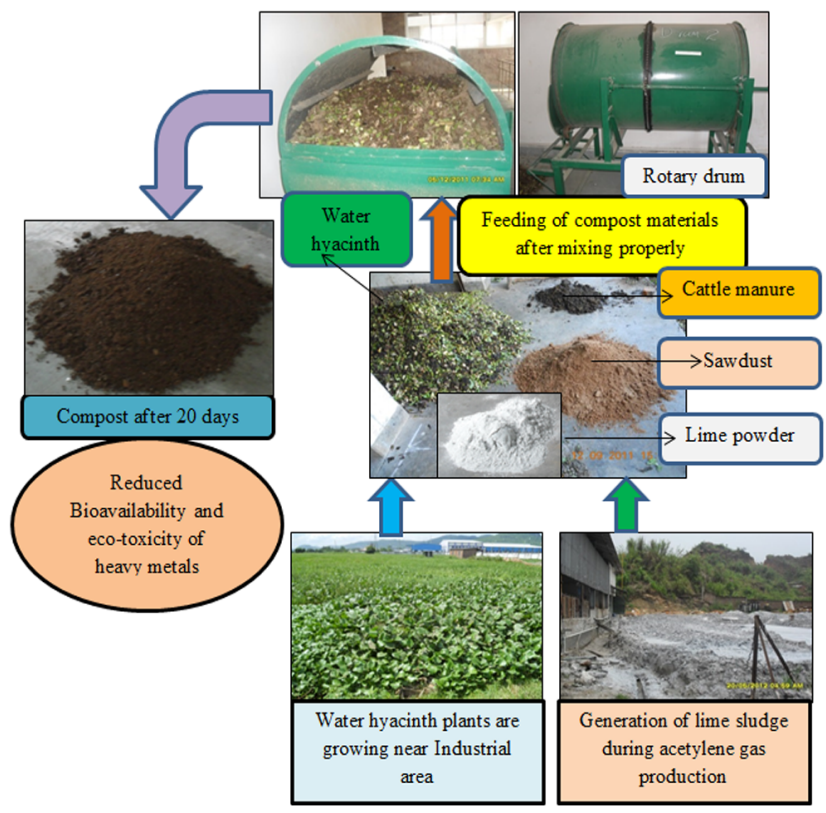

Fig 1. Schematic view of the rotary drum composting process, preparation of compost materials and collection of raw materials.

\subsection{Experimental and Analysis}

A pilot-scale rotary drum composter with a capacity of $550 \mathrm{~L}$ was designed and operated in the batch-mode [4]. A digital thermometer was used for temperature monitoring throughout the composting process. Each sample was analyzed for the following parameters: $\mathrm{pH}$ (1:10 w/v waste: water extract), moisture content and total organic carbon (TOC) [1]. The moisture content and TOC of the compost samples were calculated according to Eqs. (1) and (2) as follows:

Moisture content $(\%)=\frac{\text { Initial weight }- \text { Final Weight }}{\text { Initial weight }} \times 100$

TOC of compost sample was determined according to Kalamdhad et al. [1] given in Eq. (2) as follows:

$$
\operatorname{TOC}(\%)=\frac{\text { Volatile solid(\%) }}{1.8}
$$

Volatile solid was determined by loss ignition method [1]. A 10-gram sample was placed in a crucible and kept in a muffle furnace at $550^{\circ} \mathrm{C}$ for $2 \mathrm{~h}$. The percentage reduction weight was calculated ((initial weight - final weight)/initial weight) for the volatile solid content. A flame atomic absorption spectrometer (FAAS) (Spectra 55B; Varian, USA) was used to analyze the total concentration of $\mathrm{Zn}, \mathrm{Cu}, \mathrm{Mn}, \mathrm{Fe}, \mathrm{Ni}, \mathrm{Pb}, \mathrm{Cd}$ and $\mathrm{Cr}$ after digestion of $0.2 \mathrm{~g}$ sample with $10 \mathrm{~mL}$ of a mixture of $\mathrm{H}_{2} \mathrm{SO}_{4}$ (Purity $98 \%$, Loba Chemicals; North East Chemical Corporation, India) and $\mathrm{HclO}_{4}$ (5:1) (purity of $\mathrm{HclO}_{4}: 70 \%$, Merck Chemicals; A. B. Chemicals and Instruments, India) digested in a block digestion system (Pelican Equipments, India) for $2 \mathrm{~h}$ at $300^{\circ} \mathrm{C}$.

The HM concentration was determined using the following Eq. (3):

$\mathrm{HM}$ concentration $(\mathrm{mg} / \mathrm{kg})=$

$$
\frac{\mathrm{HM} \text { concentration }\left(\frac{\mathrm{mg}}{\mathrm{L}}\right) \times \text { volume of 6iquid }(\mathrm{mL})}{\text { Weight of solid sample }(\mathrm{g})}
$$

\subsection{Fractionation Procedure of $\mathrm{HMs}$}

Sequential extraction was carried out according to the procedure given by Tessier et al. [10] to yield five fractions: exchangeable (EXCH), carbonate (CARB), reducible (RED), organic bound fraction $(\mathrm{OMB})$, and residual (RESI). The sequential extraction was carried in polypropylene centrifuge tubes of $50 \mathrm{~mL}$ capacity. After each successive extraction and centrifugation at 10,000 rpm for $5 \mathrm{~min}$, the supernatant liquid was removed with a pipette and made up to the volumes required for the HM analyses. The residue obtained after each consecutive extraction was washed with $20 \mathrm{~mL}$ of Milli Q water by shaking for 15 minutes followed by centrifugation without loss of solids. The extraction solutions were stored in polyethylene bottles for HM analysis. All extractions were performed in triplicate and the mean values were presented with their standard deviations. FAAS was used for analysis of different HM fractions. The sequential extraction has already been reported in detail [8]. 
The bioavailability factor (BAF) for HMs was calculated according to Tessier et al. [10] and Singh and Kalamdhad [11] as follows:

$$
\mathrm{BAF}=\frac{\mathrm{EXCH}+\mathrm{CARB}+\mathrm{RED}+\mathrm{OMB}}{\text { Total concentration of } \mathrm{HM}} \times 100
$$

All the extractions/experiments were carried out in triplicate of all collected samples in different days. Metal determinations for both the total metal and that extracted by sequential procedure were analyzed by FAAS. A $1000 \mathrm{mg} / \mathrm{L}$ concentration of standard solution was purchased from Merck Ltd, India. All desired concentrations of standards were prepared in the laboratory to minimize the sources of error. Blanks were run simultaneously for all the metal determinations.

\subsection{Recovery Rate Analysis}

The recovery of HM during the sequential extraction procedure was investigated by comparing the sum of each fraction's concentration with the total HM concentrations. The sequential extraction procedure results were checked by comparing the sum of the five fractions (EXCH, CARB, RED, OMB and RESI) with the total $\mathrm{HM}$ concentrations $(\mathrm{mg} / \mathrm{kg})$ according to the following equation:

Recovery $(\%)=\frac{\mathrm{EXCH}+\mathrm{CARB}+\mathrm{RED}+\mathrm{OMB}+\mathrm{RESI}}{\text { Total concentration of HM }} \times 100(5)$

\section{2,5, Risk Assessment Code (RAC)}

A risk assessment code (RAC) was also applied to estimate the environmental risk associated with $\mathrm{HM}$ pollution in water hyacinth compost. This method has been used widely by several researchers for assessing HM pollution in sediments/soils [12]. RAC measures the bioavailability of metals by applying a scale to the percentage of metals present in the sum of EXCH and CARB fractions, because these fractions are weakly bonded, easily affected by ionic strength, and vulnerable to $\mathrm{pH}$ changes in soil environment [13]. The high mobility of EXCH and CARB fractions could equilibrate with the aqueous phase and consequently become more rapidly bioavailable [12]. Table 1classifies the risk categorized in terms of RAC. RAC was calculated as follows:

$$
\mathrm{RAC}(\%)=\frac{\mathrm{EXCH}+\mathrm{CARB}}{\text { Total concentration of HM}} \times 100
$$

The present study results were given as the mean values \pm standard deviations. Analysis of variance (ANOVA) was performed using the SPSS software (M/S. SPSS South Asia (P) Ltd, India).

Table 1. Risk Assessment Code (RAC) [12]

\begin{tabular}{ccc}
\hline Category & Risk & $\begin{array}{c}\text { HMs in EXCH and CARB Fractions } \\
\text { (\% of Total HMs) }\end{array}$ \\
\hline 1 & No risk & $<1$ \\
2 & Low risk & $1-10$ \\
3 & Medium risk & $11-30$ \\
4 & High risk & $31-50$ \\
5 & Very high risk & $>50$ \\
\hline
\end{tabular}

\section{Results and Discussion}

\subsection{Physico-Chemical Analysis}

The moisture content, temperature, organic carbon and $\mathrm{pH}$ are the most important parameters for the immobilization of HMs in composting process. The details of physicochemical parameters are given elsewhere [9]. As shown in Fig. 2a, the temperature rose sharply within $5 \mathrm{~h}$ of feeding the composting mixture into the reactor and the thermophilic temperature was measured in the range of $56-60^{\circ} \mathrm{C}$ during the composting process. The longest thermophilic stage occurred in the lime treatments, as compared to the control. The temperature was increased after each turning due to the decomposition of partially or semi decomposed materials which had been transferred from anaerobic to aerobic conditions [14]. The addition of the optimum percentage of lime was favorable for composting process, whereas excess lime (3\%) degraded the composting process might be due to the reduced metabolic activity of microbes at high $\mathrm{pH}$ [15]. Fig. 2b shows that the moisture content of the composting mixture was significantly $(p<0.001)$ decreased by $24-27 \%$ during the composting process. The greatest reduction of moisture content was found in control and lime treatment 1 , followed by lime treatments 2 and 3 . This was attributed to the action of lime in increasing the moisture holding capacity of the composting materials during the composting process [16].

As shown in Fig. 2c, the $\mathrm{pH}$ was increased for all three lime treatments at the initial stage of the composting process, but was reduced from alkaline to neutral at the mature composting stage. Alkaline lime could neutralize the organic acids released during the composting process [16]. The $\mathrm{pH}$ was significantly increased ( $p<0.001$ ) from 6.6 to 7.4 , from 7.5 to 7.4 , from 8.5 to 7.6 , and from 10.4 to 7.7 in the control, and lime treatments 1,2 , and 3 , respectively. The TOC was reduced significantly $(p<0.001)$ from 36 to $24 \%, 34$ to $19 \%, 35$ to $19 \%$, and 30 to $22 \%$ in control, and lime treatments 1, 2, and 3, respectively (Fig. 2d). The maximum TOC reduction occurred in lime treatment 2 (46.1\%), followed by lime treatment 1 (44.6\%), control (32.6\%), and lime treatment $3(28.1 \%)$ treatments. The decrease in TOC during the composting process is consistent with the decomposition of the organic matter through microbe respiration in the form of $\mathrm{CO}_{2}$, mineralization of decomposed organic matter, and assimilation of the readily available carbon by microbes [17].

The total HM contents ( $\mathrm{Zn}, \mathrm{Cu}, \mathrm{Mn}, \mathrm{Fe}, \mathrm{Ni}, \mathrm{Pb}, \mathrm{Cd}$ and $\mathrm{Cr}$ ) in the composting of water hyacinth are presented in Tables 3, 4, 5 and 6, along with their different fractions. These HMs were concentrated in the composting process due to weight loss in the course of aerobic degradation of organic matter during the process [18]. The increment of total HM concentration in the compost is likely to increase the environmental HM risk. However, as discussed in the material and methods section, the bioavailability and eco-toxicity of HMs in the compost depend mainly on their specific chemical forms [3].

\subsection{Fractionation of $\mathrm{HMs}$}

The EXCH fraction metals are most readily available to living organisms. Metals bound with CARB fraction are very sensitive to $\mathrm{pH}$ changes and can be leached out at lower $\mathrm{pH}$. These metal 

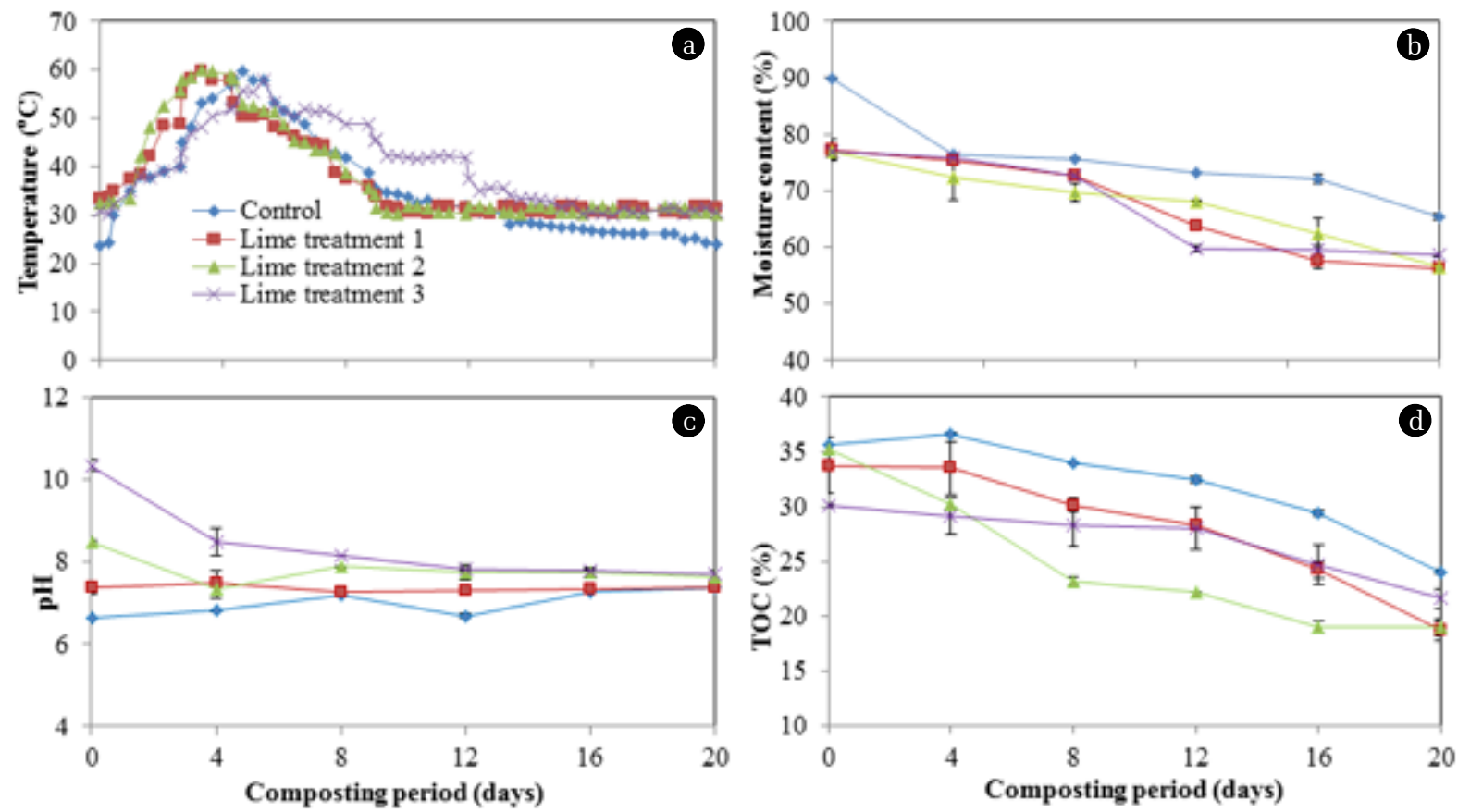

Fig. 2. Variation of physicochemical parameters: (a) temperature, (b) moisture content, (c) pH and (d) TOC during the composting process (bars denoted as \pm standard deviation).

Table 2. Summary of ANOVA Results of Different Fractions of HMs in Control, and Lime Treatments 1, 2 and 3

\begin{tabular}{|c|c|c|c|c|c|c|}
\hline \multirow{2}{*}{ Heavy metals } & \multirow{2}{*}{$\begin{array}{l}\text { ANOVA } \\
\text { statistics }\end{array}$} & \multicolumn{5}{|c|}{ Fractions } \\
\hline & & EXCH & CARB & RED & OMB & RESI \\
\hline \multirow{2}{*}{$\mathrm{Zn}$} & $F$ & 8.4 & 43.0 & 20.2 & 19.6 & 9.7 \\
\hline & $p$-value & 0.000 & 0.000 & 0.000 & 0.000 & 0.000 \\
\hline \multirow{2}{*}{$\mathrm{Cu}$} & $F$ & 29.6 & 11.8 & 46.3 & 8.3 & 14.1 \\
\hline & $p$-value & 0.000 & 0.000 & 0.000 & 0.000 & 0.000 \\
\hline \multirow{2}{*}{ Mn } & $F$ & 21.1 & 75.1 & 28.0 & 47.3 & 26.7 \\
\hline & $p$-value & 0.000 & 0.000 & 0.000 & 0.000 & 0.000 \\
\hline \multirow{2}{*}{$\mathrm{Fe}$} & $F$ & 126.7 & 8.7 & 54.7 & 16.0 & 39.4 \\
\hline & $p$-value & 0.000 & 0.000 & 0.000 & 0.000 & 0.000 \\
\hline \multirow{2}{*}{$\mathrm{Ni}$} & $F$ & 9.6 & 14.8 & - & - & 12.0 \\
\hline & $p$-value & 0.000 & 0.000 & - & - & 0.000 \\
\hline \multirow{2}{*}{$\mathrm{Pb}$} & $F$ & 16.2 & 27.3 & - & - & 8.5 \\
\hline & $p$-value & 0.000 & 0.000 & - & - & 0.000 \\
\hline \multirow{2}{*}{$\mathrm{Cd}$} & $F$ & 28.6 & 8.5 & - & - & 6.6 \\
\hline & $p$-value & 0.000 & 0.000 & - & - & 0.000 \\
\hline \multirow{2}{*}{$\mathrm{Cr}$} & $F$ & 12.9 & 14.6 & 20.2 & 50.8 & 15.4 \\
\hline & $p$-value & 0.000 & 0.000 & 0.000 & 0.000 & 0.000 \\
\hline
\end{tabular}

$F=$ likelihood ratio, $p=$ probability

fractions are considered the most bioavailable fractions. The RED and $\mathrm{OMB}$ fractions of metals are not considered mobile or bioavailable to living organisms. The RED fraction consists of iron and manganese oxides that are thermodynamically unstable at anoxic conditions. The OMB metal fraction is bound with humic substances, which can release under oxidizing conditions. The RESI metal fraction is retained within the crystal lattices of minerals and inside crystallized oxides. This fraction is usually not expected to be released in the short term at normal natural conditions [5, 7]. The rotary drum composting of water hyacinth with waste lime exhibited significant $(p<0.001)$ changes in the different HM fractions (EXCH, CARB, RED, OMB and RESI), as shown in Table 2. 


\subsubsection{Zinc $(Z n)$}

The fractionation of $\mathrm{Zn}$ in control, and lime treatments 1,2 and 3 is presented in Tables 2, 3, 4, and 5, respectively. Most mobile fractions (EXCH and CARB) of Zn were reduced in control and all three the lime treatments. The greatest reduction of EXCH and CARB fractions was about $81 \%$ and $89 \%$, respectively, in the final compost of lime treatment 1 (Table 3). The significant reduction $(p<0.001)$ of EXCH and CARB fractions was attributed to conversion of these fractions into RED and RESI fractions during the composting process. As compared to control, the RESI fraction of $\mathrm{Zn}$ was increased to the greatest extent in all three lime treatments and became dominant. The RED fraction of $\mathrm{Zn}$ increased in all three treatments as compared to control. These results confirm that waste lime was highly efficient for reducing the bioavailable fractions of $\mathrm{Zn}$ due to conversion of these fractions in to inert fraction (RESI). Zhu et al. [19] reported that Zn was mainly found in RED and OMB fractions in sewage sludge and humus soil. However, in the present study, it was mainly found as the RESI fraction. The reduction of EXCH, CARB and OMB fractions in the compost of control and all three lime treatments was attributed to the complexation of $\mathrm{Zn}$ with humic substances [21]. The most mobile fractions of $\mathrm{Zn}$ were transformed into less mobile fractions (RED and OMB) and inert fraction (RESI fraction), along with stabilization of organic matter during the composting process [21].

\subsubsection{Copper $(\mathrm{Cu})$}

The EXCH, CARB, RED and OMB fractions of $\mathrm{Cu}$ were reduced to the ranges of $63.2-81.3 \%, 21.8-61.5 \%, 5.0-82.4 \%$ and $16.2-40.0 \%$, respectively, in the final compost of control and all three lime treatments. The greatest reduction of EXCH, CARB and RED fractions occurred in lime treatment 2 (Table 5). The smallest reduction of all mobile fractions occurred in lime treatment 3. One or more organic functional groups, mainly carboxylic, carbonyl, and phenolic groups, was present in the final compost, which allowed these groups to bind the EXCH and CARB fractions of $\mathrm{Cu}$ [19]. Cu occurred mainly in the RESI fraction in the compost of control and all three lime treatments. This suggested that the addition of lime effectively hindered the bioavailability of $\mathrm{Cu}$ during rotary drum composting. Wong and Selvam [15] reported the following order of $\mathrm{Cu}$ fractions in control and lime amended sewage sludge compost: OMB > RESI $>$ RED $>$ EXCH $>$ CARB. In the present study, the order of $\mathrm{Cu}$ fractions in control was RESI $>\mathrm{OMB}>\mathrm{RED}>\mathrm{CARB}>\mathrm{EXCH}$, and in lime amended compost was RESI $>\mathrm{OMB}>$ EXCH $>$ CARB $>$ RED. The distribution of $\mathrm{Cu}$ in control, and lime treatments 1,2 , and 3 are presented in Tables 3, 4, 5, and 6, respectively.

\subsubsection{Manganese (Mn)}

The EXCH fraction of $\mathrm{Mn}$ was reduced in control and all three lime treatments. However, lime treatment 2 exhibited the greatest reduction of about $66 \%$. Tables 3, 4, 5, and 6 reveal the changes in the $\mathrm{Mn}$ fractionation in control, and lime treatments 1,2 , and 3 , respectively. The CARB fraction was reduced in all three lime treatments, but increased in the control. The RED and RESI fractions of $\mathrm{Mn}$ were increased in the final compost of control and all three lime treatments. Wong and Selvam [15] reported the following order of different $\mathrm{Mn}$ fractions in control and lime amended sewage sludge compost: RED > RESI > EXCH > CARB > OMB. However, this order in the present study was RESI $>$ CARB $>$ RED $>$ EXCH $>\mathrm{OMB}$ in control and RESI $>\mathrm{RED}>\mathrm{CARB}>\mathrm{EXCH}>\mathrm{OMB}$ in the final compost of all three lime treatments. These orders reveal that the CARB fraction was second dominant in control, but that the RED fraction was second dominant in the lime treatments. These results suggested that the CARB fraction was converted into RED and RESI fractions due to the lime addition.

\subsubsection{Iron (Fe)}

The EXCH fraction of Fe was reduced in control and lime treatment 1, but enhanced in lime treatments 2 and 3. The CARB and RED

Table 3. Changes in the Fractionation of HMs in Control during 20-day Composting Period (mean $\pm S D, n=3$ )

\begin{tabular}{|c|c|c|c|c|c|c|c|c|c|c|}
\hline \multirow{2}{*}{$\begin{array}{l}\text { Heavy } \\
\text { metals }\end{array}$} & \multirow{2}{*}{ Days } & \multicolumn{5}{|c|}{ Fractions (mg/kg) } & \multirow{2}{*}{$\begin{array}{c}\text { Sum of fractions } \\
(\mathrm{mg} / \mathrm{kg})\end{array}$} & \multirow{2}{*}{$\begin{array}{c}\text { Total HM } \\
\text { (mg/kg) }\end{array}$} & \multirow{2}{*}{$\begin{array}{l}\text { Error } \\
(\%)\end{array}$} & \multirow{2}{*}{$\begin{array}{c}\text { Recovery } \\
\text { (\%) }\end{array}$} \\
\hline & & EXCH & CARB & RED & OMB & RESI & & & & \\
\hline \multirow{2}{*}{$\mathrm{Zn}$} & 0 & $4.3 \pm 0.6$ & $12.7 \pm 0.5$ & $14.4 \pm 0.5$ & $21.3 \pm 2.4$ & $90 \pm 4.7$ & 142.2 & $147 \pm 1.9$ & 3.5 & 96.5 \\
\hline & 20 & $2.0 \pm 0.03$ & $5.8 \pm 0.3$ & $6.7 \pm 1.1$ & $21.2 \pm 0.8$ & $119 \pm 3.0$ & 154.7 & $155 \pm 2.9$ & 0.3 & 99.7 \\
\hline \multirow{2}{*}{$\mathrm{Cu}$} & 0 & $3.4 \pm 0.13$ & $2.4 \pm 0.23$ & $2.0 \pm 0.2$ & $26.5 \pm 0.5$ & $31.3 \pm 3.3$ & 65.6 & $70.5 \pm 1.0$ & 7.0 & 93.0 \\
\hline & 20 & $0.9 \pm 0.08$ & $1.1 \pm 0.13$ & $1.7 \pm 0.1$ & $15.9 \pm 0.2$ & $71.1 \pm 0.2$ & 90.6 & $91.6 \pm 1.9$ & 1.0 & 99.0 \\
\hline \multirow{2}{*}{$\mathrm{Mn}$} & 0 & $145 \pm 3.3$ & $90 \pm 3.6$ & $61.4 \pm 2.0$ & $80.6 \pm 2.2$ & $142 \pm 7.3$ & 519.6 & $538 \pm 18$ & 3.3 & 96.7 \\
\hline & 20 & $62.0 \pm 0.3$ & $121.8 \pm 1.6$ & $97.2 \pm 1.0$ & $54.2 \pm 3.4$ & $320 \pm 1.6$ & 655.9 & $658 \pm 13$ & 0.3 & 99.7 \\
\hline \multirow{2}{*}{$\mathrm{Fe}$} & 0 & $44.7 \pm 0.9$ & $28.2 \pm 0.2$ & $2485 \pm 4.5$ & $6386 \pm 489$ & $1953 \pm 86$ & 10896.3 & $11030 \pm 340$ & 1.2 & 98.8 \\
\hline & 20 & $10.6 \pm 0.7$ & $33.6 \pm 1.3$ & $2902 \pm 30$ & $4639 \pm 66$ & $6059 \pm 595$ & 13673.2 & $14105 \pm 415$ & 3.1 & 96.9 \\
\hline \multirow{2}{*}{$\mathrm{Ni}$} & 0 & $5.3 \pm 0.1$ & $3.9 \pm 0.05$ & ND & ND & $215 \pm 14.1$ & 223.8 & $240 \pm 10.5$ & 6.6 & 93.5 \\
\hline & 20 & $2.0 \pm 0.1$ & $1.4 \pm 0.5$ & ND & ND & $237 \pm 4.0$ & 240.5 & $244 \pm 2.5$ & 1.3 & 98.6 \\
\hline \multirow{2}{*}{$\mathrm{Pb}$} & 0 & $25.0 \pm 1.2$ & $15.6 \pm 0.8$ & ND & $\mathrm{ND}$ & $895 \pm 40.4$ & 935.9 & $958 \pm 7.5$ & 2.3 & 97.7 \\
\hline & 20 & $6.5 \pm 0.6$ & $7.4 \pm 1.2$ & ND & ND & $1057 \pm 58$ & 1070.8 & $1111 \pm 53$ & 3.6 & 96.4 \\
\hline \multirow{2}{*}{$\mathrm{Cd}$} & 0 & $1.1 \pm 0.16$ & $1.1 \pm 0.12$ & ND & $\mathrm{ND}$ & $47.5 \pm 0.6$ & 49.7 & $51.5 \pm 1.0$ & 3.5 & 96.6 \\
\hline & 20 & $0.4 \pm 0.05$ & $0.7 \pm 0.03$ & ND & ND & $54.1 \pm 0.3$ & 55.1 & $60.7 \pm 1.7$ & 9.1 & 90.9 \\
\hline \multirow{2}{*}{$\mathrm{Cr}$} & 0 & $5.8 \pm 0.3$ & $1.8 \pm 0.3$ & $3.4 \pm 0.2$ & $15.4 \pm 0.3$ & $28.5 \pm 3.5$ & 54.9 & $59.3 \pm 3.2$ & 7.4 & 92.6 \\
\hline & 20 & $3.88 \pm 0.08$ & $1.4 \pm 0.0$ & $0.8 \pm 0.1$ & $4.3 \pm 0.3$ & $62.8 \pm 2.6$ & 73.1 & $76.3 \pm 2.4$ & 4.1 & 95.9 \\
\hline
\end{tabular}

Mean values in columns are statistically different (ANOVA; $p<0.05$ )

ND: not detected 
fractions of $\mathrm{Fe}$ were reduced in all three lime treatments as compared to control. The greatest reduction of these fractions was about $81.4 \%$ and $53.0 \%$ in lime treatment 1 . The OMB fractions of Fe were decreased in the control and all three lime treatments. The RESI fraction of Fe was increased during the composting process. The OMB fraction was dominant at the initial stage but Fe was mainly found in the RESI fraction at end of the composting process. The order of the different fractions of $\mathrm{Fe}$ was $\mathrm{RESI}>\mathrm{OMB}>\mathrm{RED}>\mathrm{EXCH}>$ CARB in control and all three treatments. The Fe distributions in the various fractions in the control and lime treatments 1, 2 and 3 are illustrated in Tables 3, 4, 5, and 6, respectively.

\subsubsection{Nickel (Ni)}

The EXCH and CARB fractions of Ni were reduced significantly $(p<0.001)$ in the range of $48-96.4 \%$ and $53.1-80.1 \%$, respectively, in control and all three lime treatments. The greatest reduction of EXCH and CARB fractions occurred in lime treatment 1, followed by lime treatment 2 , control and lime treatment 3 . The RESI fraction of $\mathrm{Ni}$ was increased significantly $(p<0.001)$ in control and all three lime treatments. The study of Wong and Selvam [15] concluded that the order of $\mathrm{Ni}$ fractions in control and lime amended sewage sludge compost was: RESI $>$ RED $>$ OMB $>$ CARB $>$ EXCH. However, in the present study, this order was RESI $>$ EXCH

Table 4. Variations in the Fractionation of HMs in Lime Treatment 1 during 20-day Composting Period (mean \pm SD, $n=3$ )

\begin{tabular}{|c|c|c|c|c|c|c|c|c|c|c|}
\hline \multirow{2}{*}{$\begin{array}{l}\text { Heavy } \\
\text { metals }\end{array}$} & \multirow{2}{*}{ Days } & \multicolumn{5}{|c|}{ Fractions (mg/kg) } & \multirow{2}{*}{$\begin{array}{c}\text { Sum of fractions } \\
(\mathrm{mg} / \mathrm{kg})\end{array}$} & \multirow{2}{*}{$\begin{array}{c}\text { Total HM } \\
\text { (mg/kg) }\end{array}$} & \multirow{2}{*}{$\begin{array}{c}\text { Error } \\
(\%)\end{array}$} & \multirow{2}{*}{$\begin{array}{c}\text { Recovery } \\
\text { (\%) }\end{array}$} \\
\hline & & EXCH & CARB & RED & OMB & RESI & & & & \\
\hline \multirow{2}{*}{$\mathrm{Zn}$} & 0 & $5.7 \pm 0.1$ & $9.9 \pm 0.7$ & $32.8 \pm 0.7$ & $24.5 \pm 4.4$ & $51.3 \pm 4.0$ & 124.2 & $137 \pm 2.5$ & 9.0 & 91.0 \\
\hline & 20 & $1.1 \pm 0.05$ & $1.1 \pm 0.0$ & $34.6 \pm 1.3$ & $7.0 \pm 1.7$ & $104.6 \pm 4.7$ & 148.3 & $154 \pm 0.2$ & 3.7 & 96.3 \\
\hline \multirow{2}{*}{$\mathrm{Cu}$} & 0 & $9.85 \pm 0.40$ & $2.47 \pm 0.09$ & $0.59 \pm 0.09$ & $10.87 \pm 0.83$ & $9.38 \pm 1.13$ & 33.2 & $33.6 \pm 2$ & 1.2 & 98.8 \\
\hline & 20 & $2.3 \pm 0.16$ & $1.23 \pm 0.18$ & $0.39 \pm 0.09$ & $6.5 \pm 0.03$ & $47.92 \pm 0.08$ & 58.2 & $63.2 \pm 3.3$ & 7.8 & 92.2 \\
\hline \multirow{2}{*}{$\mathrm{Mn}$} & 0 & $24.0 \pm 3.3$ & $122 \pm 3.6$ & $115 \pm 2.0$ & $34.4 \pm 2.2$ & $160 \pm 7.3$ & 453.8 & $469.0 \pm 16$ & 3.1 & 96.7 \\
\hline & 20 & $15.0 \pm 0.3$ & $74 \pm 1.6$ & $117 \pm 1.0$ & $11.0 \pm 3.4$ & $269 \pm 1.6$ & 485.1 & $535.0 \pm 23$ & 9.3 & 90.7 \\
\hline \multirow{2}{*}{$\mathrm{Fe}$} & 0 & $122 \pm 1.5$ & $22.7 \pm 0.8$ & $2207 \pm 106$ & $3283 \pm 581$ & $2062 \pm 128$ & 7695.7 & $8220 \pm 0.0$ & 6.4 & 93.6 \\
\hline & 20 & $73.9 \pm 3.9$ & $4.2 \pm 1.0$ & $1039 \pm 8.5$ & $1184 \pm 39.2$ & $9534 \pm 34$ & 11834 & $12715 \pm 500$ & 7.7 & 92.3 \\
\hline \multirow{2}{*}{$\mathrm{Ni}$} & 0 & $1.9 \pm 0.5$ & $3.7 \pm 0.2$ & $\mathrm{ND}$ & $\mathrm{ND}$ & $177 \pm 3.9$ & 182.3 & $199 \pm 4.0$ & 8.2 & 91.8 \\
\hline & 20 & $0.07 \pm 0.02$ & $0.7 \pm 0.14$ & $\mathrm{ND}$ & $\mathrm{ND}$ & $259.5 \pm 3.5$ & 260.3 & $265 \pm 5.1$ & 1.8 & 98.2 \\
\hline \multirow{2}{*}{$\mathrm{Pb}$} & 0 & $10.7 \pm 0.4$ & $14.7 \pm 0.2$ & $\mathrm{ND}$ & $\mathrm{ND}$ & $640 \pm 4.6$ & 665.7 & $677 \pm 23.5$ & 1.6 & 98.4 \\
\hline & 20 & $1.65 \pm 0.2$ & $3.9 \pm 0.3$ & $\mathrm{ND}$ & $\mathrm{ND}$ & $877 \pm 22$ & 882.6 & $905 \pm 49.5$ & 2.4 & 97.6 \\
\hline \multirow{2}{*}{$\mathrm{Cd}$} & 0 & $1.0 \pm 0.0$ & $0.94 \pm 0.04$ & $\mathrm{ND}$ & $\mathrm{ND}$ & $44.7 \pm 2.2$ & 46.7 & $48.7 \pm 2.1$ & 4.1 & 95.9 \\
\hline & 20 & $0.13 \pm 0.03$ & $0.3 \pm 0.03$ & $\mathrm{ND}$ & $\mathrm{ND}$ & $60.6 \pm 0.4$ & 61.05 & $62.0 \pm 6.9$ & 1.5 & 98.6 \\
\hline \multirow{2}{*}{$\mathrm{Cr}$} & 0 & $2.3 \pm 0.5$ & $2.6 \pm 0.6$ & $3.2 \pm 0.1$ & $5.4 \pm 0.3$ & $81 \pm 1.5$ & 94.0 & $101 \pm 5.0$ & 7.0 & 93.0 \\
\hline & 20 & $0.4 \pm 0.0$ & $0.93 \pm 0.1$ & $0.8 \pm 0.1$ & $3.0 \pm 0.0$ & $126 \pm 5.7$ & 130.9 & $142 \pm 3.0$ & 7.5 & 92.5 \\
\hline
\end{tabular}

Mean values in columns are statistically different (ANOVA; $p<0.05$ )

ND: not detected

Table 5. Variation in the Fractionation of HMs in Lime Treatment 2 during 20-day Composting Period $(\operatorname{mean} \pm \mathrm{SD}, \mathrm{n}=3$ )

\begin{tabular}{|c|c|c|c|c|c|c|c|c|c|c|}
\hline \multirow{2}{*}{$\begin{array}{l}\text { Heavy } \\
\text { metals }\end{array}$} & \multirow{2}{*}{ Days } & \multicolumn{5}{|c|}{ Fractions (mg/kg) } & \multirow{2}{*}{$\begin{array}{c}\text { Sum of fractions } \\
(\mathrm{mg} / \mathrm{kg})\end{array}$} & \multirow{2}{*}{$\begin{array}{c}\text { Total HM } \\
\text { (mg/kg) }\end{array}$} & \multirow{2}{*}{$\begin{array}{l}\text { Error } \\
(\%)\end{array}$} & \multirow{2}{*}{$\begin{array}{c}\text { Recovery } \\
\text { (\%) }\end{array}$} \\
\hline & & EXCH & CARB & RED & OMB & RESI & & & & \\
\hline \multirow{2}{*}{$\mathrm{Zn}$} & 0 & $6.4 \pm 0.4$ & $16.6 \pm 0.2$ & $35.1 \pm 0.4$ & $21.3 \pm 0.8$ & $51.0 \pm 1.0$ & 130.4 & $135 \pm 0.4$ & 3.6 & 96.4 \\
\hline & 20 & $2.1 \pm 0.8$ & $4.2 \pm 0.6$ & $36.0 \pm 0.8$ & $9.9 \pm 0.3$ & $93.5 \pm 1.5$ & 145.6 & $155 \pm 1.8$ & 6.0 & 94.0 \\
\hline \multirow{2}{*}{$\mathrm{Cu}$} & 0 & $6.0 \pm 0.3$ & $2.8 \pm 0.5$ & $1.7 \pm 0.1$ & $12.5 \pm 0.1$ & $12.8 \pm 2.6$ & 35.8 & $37.2 \pm 1.8$ & 3.7 & 96.3 \\
\hline & 20 & $1.1 \pm 0.1$ & $1.1 \pm 0.0$ & $0.3 \pm 0.1$ & $9.1 \pm 0.7$ & $47.5 \pm 2.1$ & 59.1 & $64.9 \pm 4.1$ & 9.0 & 91.0 \\
\hline \multirow{2}{*}{$\mathrm{Mn}$} & 0 & $41.4 \pm 4.0$ & $131 \pm 1.4$ & $119 \pm 6$ & $19.9 \pm 1.4$ & $49.2 \pm 5.8$ & 360.4 & $362 \pm 22.3$ & 0.4 & 99.6 \\
\hline & 20 & $14.1 \pm 0.1$ & $72.5 \pm 5.8$ & $173 \pm 15$ & $10.9 \pm 0.9$ & $230 \pm 15$ & 500.6 & $523 \pm 14.5$ & 4.2 & 95.8 \\
\hline \multirow{2}{*}{$\mathrm{Fe}$} & 0 & $122 \pm 11.5$ & $23.1 \pm 0.5$ & $2126 \pm 186$ & $2517 \pm 357$ & $1567 \pm 33$ & 6354.6 & $6572.5 \pm 483$ & 3.3 & 96.7 \\
\hline & 20 & $149 \pm 11$ & $15.3 \pm 30$ & $1208 \pm 161$ & $1737 \pm 507$ & $7433 \pm 66$ & 10543.6 & $11000 \pm 945$ & 4.2 & 95.9 \\
\hline \multirow{2}{*}{$\mathrm{Ni}$} & 0 & $1.5 \pm 0.1$ & $4.0 \pm 0.5$ & ND & ND & $191 \pm 2.6$ & 196.8 & $216 \pm 21.3$ & 8.8 & 91.2 \\
\hline & 20 & $0.09 \pm 0.002$ & $1.1 \pm 0.01$ & ND & ND & $257.5 \pm 3.5$ & 258.7 & $264 \pm 6.7$ & 1.9 & 98.1 \\
\hline \multirow{2}{*}{$\mathrm{Pb}$} & 0 & $16.2 \pm 0.2$ & $14.2 \pm 0.8$ & ND & ND & $683 \pm 52.4$ & 713.8 & $764 \pm 11$ & 6.6 & 93.4 \\
\hline & 20 & $2.43 \pm 0.07$ & $3.07 \pm 0.27$ & ND & $\mathrm{ND}$ & $898 \pm 1.5$ & 903.0 & $917 \pm 37$ & 1.5 & 98.5 \\
\hline \multirow{2}{*}{$\mathrm{Cd}$} & 0 & $0.87 \pm 0.02$ & $0.86 \pm 0.01$ & ND & ND & $37.5 \pm 5$ & 39.2 & $42.2 \pm 3.4$ & 6.9 & 93.1 \\
\hline & 20 & $0.33 \pm 0.03$ & $0.53 \pm 0.17$ & $\mathrm{ND}$ & ND & $56.8 \pm 1.7$ & 57.6 & $60.2 \pm 4.7$ & 4.3 & 95.7 \\
\hline \multirow{2}{*}{$\mathrm{Cr}$} & 0 & $1.5 \pm 0.3$ & $2.6 \pm 0.5$ & $3.2 \pm 0.1$ & $4.7 \pm 0.4$ & $78.5 \pm 3.5$ & 90.5 & $100 \pm 0.0$ & 9.1 & 91.0 \\
\hline & 20 & $0.33 \pm 0.01$ & $1.2 \pm 0.1$ & $1.6 \pm 0.3$ & $1.8 \pm 0.2$ & $140.4 \pm 1.9$ & 145.2 & $147 \pm 5.0$ & 1.2 & 98.8 \\
\hline
\end{tabular}

Mean values in columns are statistically different (ANOVA; $p<0.05$ )

ND: not detected 
$>$ CARB in control and RESI $>$ CARB $>$ EXCH in all three lime-treated composts. The order of different fractions of Ni confirmed that the EXCH fraction was converted into RESI fractions due to lime addition. According to Zhu et al. [19], Ni was mainly found in RED and OMB fractions in sewage sludge and humus soil. However, in the present study, Ni mainly occurred in the RESI fraction in control and all three lime treatments. Su and Wong [22] reported that the RESI fraction of Ni contributed 52\% of the total $\mathrm{Ni}$ content, followed by the RED fraction in sewage sludge. However, in the present study, the RESI fraction contributed about $95.6-99.7 \%$ of the total fraction. The RED and $\mathrm{OMB}$ fractions of $\mathrm{Ni}$ were not detected at any stage of the composting process. Changes in fractionations of $\mathrm{Ni}$ in control, and lime treatments 1, 2, and 3 are given in Tables 3, 4, 5 and 6, respectively.

\subsubsection{Lead $(\mathrm{Pb})$}

Similar to $\mathrm{Ni}$, the $\mathrm{EXCH}$ and CARB fractions of $\mathrm{Pb}$ were reduced in the range of $74.2-85.0 \%$ and $52.7-78.5 \%$, respectively, in control and lime treatments 1, 2, and 3 (Table 3, 4, 5 and 6). The reductions of these fractions were greater in the lime treatments than in control. The RESI fraction of $\mathrm{Pb}$ was increased and was the dominant fraction in the range of 95.7-99.4\% in the final compost of control and all three lime treatments. The RED and OMB fractions of $\mathrm{Pb}$ were not detected at any stage of the composting process. Zhu et al. [19] also reported that the RESI fraction of $\mathrm{Pb}$ was dominant in sewage sludge and humus soil. The order of different fractions was RESI > CARB $>$ EXCH in control and lime-treated compost. Wong and Selvam [15] reported that the EXCH and CARB fractions of $\mathrm{Pb}$ remained in the same order during the sewage sludge composting with lime. However, in the present study, these fractions were significantly reduced ( $p$ $<0.001$ ) during the composting process. Qiao and Ho [23] also reported that the bioavailability of $\mathrm{Pb}$ decreased during sewage composting.

\subsubsection{Cadmium $(\mathrm{Cd})$}

The fractionation of Cd in control, and lime treatments 1, 2, and 3 is presented in Tables $3,4,5$, and 6 , respectively. The reduction of $\mathrm{EXCH}$ and $\mathrm{CARB}$ fractions was in the range of $35.0-87.6 \%$ and $38.3-70.6 \%$ in control, and lime treatments 1,2 and 3. The greatest reductions of these fractions (EXCH and CARB) occurred in lime treatment1. This was attributed to the large degradation of organic matter in the rotary drum and its conversion into humic substances that formed chemical bonding with bioavailable fractions of Cd [24]. The RESI fraction of Cd was in the range of $95.5-99.3 \%$ in the control and all three lime treatments. Liu et al. [18] reported the following order of different fractions of $\mathrm{Cd}$ in sewage sludge composting $\mathrm{RED}>\mathrm{CARB}>\mathrm{OMB}>\mathrm{EXCH}$ $>$ RESI. However, in the present study, this order was RESI $>$ CARB > EXCH. The RED and OMB fractions of Cd were not detected at any stage of the composting process.

\subsubsection{Chromium $(\mathrm{Cr})$}

The EXCH, CARB, RED and OMB fractions of $\mathrm{Cr}$ were reduced significantly $(p<0.001)$ in the control and all three lime treatments (Tables 3, 4, 5 and 6). The highest reduction of EXCH and CARB fractions was detected at about 84.0 and $65.0 \%$, respectively, in lime treatment 1. Interestingly, the RED and OMB fractions of Cr were reduced more in control than in lime treatments 1 and 2. However, in lime treatments 1 and 2, EXCH and CARB fractions were reduced more than in control, which are the most bioavailable fractions. The dominant fraction of $\mathrm{Cr}$ was the RESI fraction, which was increased in control and all three lime treatments. Liu et al. [18] reported the following order of Cr fraction in sewage sludge composting OMB $>$ RESI $>$ EXCH $=$ RED $>$ CARB. While in the present study, the orders of the Cr fractions were RESI $>\mathrm{OMB}>\mathrm{EXCH}>\mathrm{CARB}>\mathrm{RED}$ in control, RESI $>\mathrm{OMB}>$ CARB $>$ RED $>$ EXCH in lime treatment 1, RESI $>\mathrm{OMB}>$ RED $>$ CARB $>$ EXCH in lime treatment 2 and RESI $>$ RED $>$ CARB $>\mathrm{OMB}>\mathrm{EXCH}$ in lime treatment 3 .

Table 6. Differences in the Fractionation of HMs in Lime Treatment 3 during 20-day Composting Period (mean \pm SD, $n=3$ )

\begin{tabular}{|c|c|c|c|c|c|c|c|c|c|c|}
\hline \multirow{2}{*}{$\begin{array}{l}\text { Heavy } \\
\text { metals }\end{array}$} & \multirow{2}{*}{ Days } & \multicolumn{5}{|c|}{ Fractions (mg/kg) } & \multirow{2}{*}{$\begin{array}{c}\text { Sum of fractions } \\
(\mathrm{mg} / \mathrm{kg})\end{array}$} & \multirow{2}{*}{$\begin{array}{c}\text { Total HM } \\
\text { (mg/kg) }\end{array}$} & \multirow{2}{*}{$\begin{array}{l}\text { Error } \\
(\%)\end{array}$} & \multirow{2}{*}{$\begin{array}{c}\text { Recovery } \\
\text { (\%) }\end{array}$} \\
\hline & & EXCH & CARB & RED & OMB & RESI & & & & \\
\hline \multirow{2}{*}{$\mathrm{Zn}$} & 0 & $9.3 \pm 0.1$ & $7.7 \pm 0.3$ & $45.0 \pm 0.3$ & $26.6 \pm 0.3$ & $43.0 \pm 0.6$ & 131.6 & $138 \pm 5.4$ & 4.6 & 95.4 \\
\hline & 20 & $4.7 \pm 1.04$ & $3.3 \pm 0.2$ & $48.1 \pm 0.3$ & $12.3 \pm 2.6$ & $86.5 \pm 7.5$ & 154.9 & $164 \pm 3.8$ & 5.3 & 94.7 \\
\hline \multirow{2}{*}{$\mathrm{Cu}$} & 0 & $3.6 \pm 0.6$ & $2.4 \pm 0.2$ & $1.3 \pm 0.03$ & $11.3 \pm 1.1$ & $10.1 \pm 0.4$ & 29.2 & $32.1 \pm 1.1$ & 9.0 & 91.0 \\
\hline & 20 & $1.3 \pm 0.1$ & $1.5 \pm 0.4$ & $1.3 \pm 0.22$ & $9.5 \pm 0.8$ & $49.7 \pm 7.7$ & 63.7 & $67.6 \pm 6.1$ & 6.5 & 93.6 \\
\hline \multirow{2}{*}{$\mathrm{Mn}$} & 0 & $14.2 \pm 0.5$ & $77.1 \pm 5.2$ & $141 \pm 1.6$ & $9.7 \pm 0.2$ & $148 \pm 2$ & 389.4 & $427 \pm 4.8$ & 8.7 & 91.3 \\
\hline & 20 & $10.2 \pm 0.1$ & $45.2 \pm 0.2$ & $178 \pm 46$ & $9.8 \pm 0.5$ & $254.6 \pm 1$ & 497.7 & $534 \pm 24.8$ & 6.7 & 93.3 \\
\hline \multirow{2}{*}{$\mathrm{Fe}$} & 0 & $27.3 \pm 5.8$ & $41.0 \pm 7.4$ & $1936 \pm 376$ & $2795 \pm 78$ & $1417 \pm 183$ & 6216.8 & $6467.5 \pm 7.5$ & 3.9 & 96.1 \\
\hline & 20 & $36.4 \pm 1.4$ & $17.3 \pm 5$ & $1083 \pm 36$ & $1842 \pm 202$ & $6683 \pm 316$ & 9663.2 & $10315 \pm 105$ & 6.3 & 93.7 \\
\hline \multirow{2}{*}{$\mathrm{Ni}$} & 0 & $2.7 \pm 0.3$ & $7.7 \pm 1.2$ & ND & ND & $193 \pm 25.4$ & 203.5 & $217 \pm 20$ & 6.0 & 94.0 \\
\hline & 20 & $1.4 \pm 0.4$ & $3.6 \pm 0.6$ & ND & ND & $267 \pm 2.5$ & 266.5 & $272 \pm 1.6$ & 2.0 & 98.0 \\
\hline \multirow{2}{*}{$\mathrm{Pb}$} & 0 & $16.3 \pm 0.3$ & $23.0 \pm 0.5$ & ND & ND & $680 \pm 40$ & 719.3 & $752 \pm 11.5$ & 4.3 & 95.7 \\
\hline & 20 & $4.0 \pm 0.5$ & $4.95 \pm 0.35$ & ND & ND & $851 \pm 91$ & 860.0 & $935 \pm 19.5$ & 8.0 & 92.0 \\
\hline \multirow{2}{*}{$\mathrm{Cd}$} & 0 & $0.82 \pm 0.04$ & $1.39 \pm 0.19$ & ND & ND & $38.0 \pm 0.5$ & 38.7 & $40.9 \pm 8.1$ & 5.4 & 94.6 \\
\hline & 20 & $0.53 \pm 0.07$ & $0.75 \pm 0.11$ & ND & ND & $60.3 \pm 6.7$ & 61.5 & $65.0 \pm 0.95$ & 5.3 & 94.7 \\
\hline \multirow{2}{*}{$\mathrm{Cr}$} & 0 & $1.1 \pm 0.1$ & $3.5 \pm 0.4$ & $3.0 \pm 0.2$ & $4.2 \pm 0.1$ & $63.5 \pm 1.5$ & 75.4 & $82 \pm 11.5$ & 8.4 & 91.6 \\
\hline & 20 & $0.9 \pm 0.2$ & $1.9 \pm 0.2$ & $2.0 \pm 0.3$ & $1.5 \pm 0.3$ & $93.1 \pm 2.9$ & 103.9 & $107 \pm 4.0$ & 2.4 & 97.6 \\
\hline
\end{tabular}

Mean values in columns are statistically different (ANOVA; $p<0.05$ )

ND: not detected 


\subsection{Bioavailability Factor (BAF)}

Fig 3 shows the reduction in the BAF of $\mathrm{Zn}, \mathrm{Cu}, \mathrm{Mn}, \mathrm{Fe}, \mathrm{Ni}$, $\mathrm{Pb}, \mathrm{Cd}$ and $\mathrm{Cr}$ in control, and lime treatments 1,2 , and 3. The greatest reduction of the $\mathrm{BAF}$ of $\mathrm{Zn}, \mathrm{Cu}, \mathrm{Fe}, \mathrm{Ni}, \mathrm{Cd}$ and $\mathrm{Cr}$ was about 46.9, 77.0, 62.1, 89.3, 83.9, and 73.0\%, respectively, in lime treatment 1 ; while the greatest reduction of $\mathrm{Mn}$ and $\mathrm{Pb}$ was about $39.8 \%$ and $85.0 \%$, respectively, in lime treatment 2 . Based on the BAF results, poor reductions were observed in control and lime treatment3, as compared to lime treatments 1 and 2 . The greater lime addition was not useful for reducing the BAF of HMs. This was attributed to the metabolic rate of composting microbes being reduced at higher $\mathrm{pH}$, which consequently reduced the composting process [25]. The order of BAF for different HMs was as follows: $\mathrm{Mn}(0.40)>\mathrm{Zn}=\mathrm{Fe}(0.20)>\mathrm{Cu}(0.16)>\mathrm{Cr}(0.03)$ $>\mathrm{Cd}=\mathrm{Pd}(0.01)>\mathrm{Ni}(0.003)$. The greatest reduction in BAF in lime-treated compost can be attributed to the conversion of most bioavailable fractions (EXCH and CARB) into inert fraction (RESI fraction). In addition, the formation of metal ion complex with two or more functional groups, mainly carboxylic, carbonyl and phenolic, occurs in humic substances, leading to the immobilization of ions in a rigid inner-sphere complex [23].
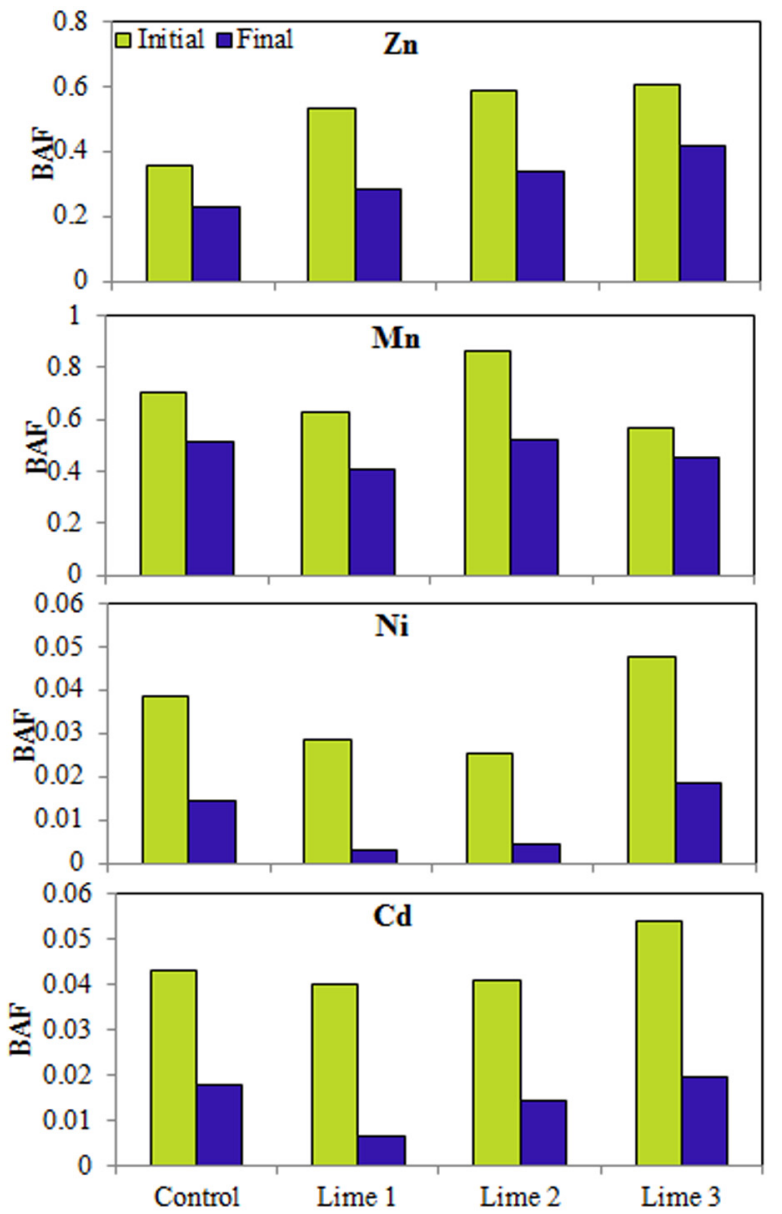

\subsection{Mechanism for Immobilization of HMs during Rotary Drum Composting with Waste Lime}

Generally two mechanisms are accountable for the immobilization of HMs in rotary drum composting with lime addition: (a) the rotary drum is a semi-closed system and highly efficient for composting due to proper agitation, holding optimum moisture, suitable aeration and mixing of the composting materials. Under the above favorable conditions, aerobic microbes flourish well and decompose into organic waste more rapidly, and are thus converted into stable humic like substance (HS) [26]. The formation of humic substances during the composting process is given below according to Zhu et al. [19].

The toxic metals bounded to organic matters and sulfides can be easily released under oxidizing conditions [27]. The general reactions are given in Eqs. (7) and (8) as follows:

Organic matter $+\mathrm{O}_{2} \stackrel{\text { Microbes }}{\longrightarrow}$ humic substances $+\mathrm{CO}_{2}+$ microbial biomass

$$
\mathrm{MS}+2 \mathrm{O}_{2} \rightarrow \mathrm{M}^{+}+\mathrm{S}
$$

where MS is metals bounded to organic matters and sulfide,
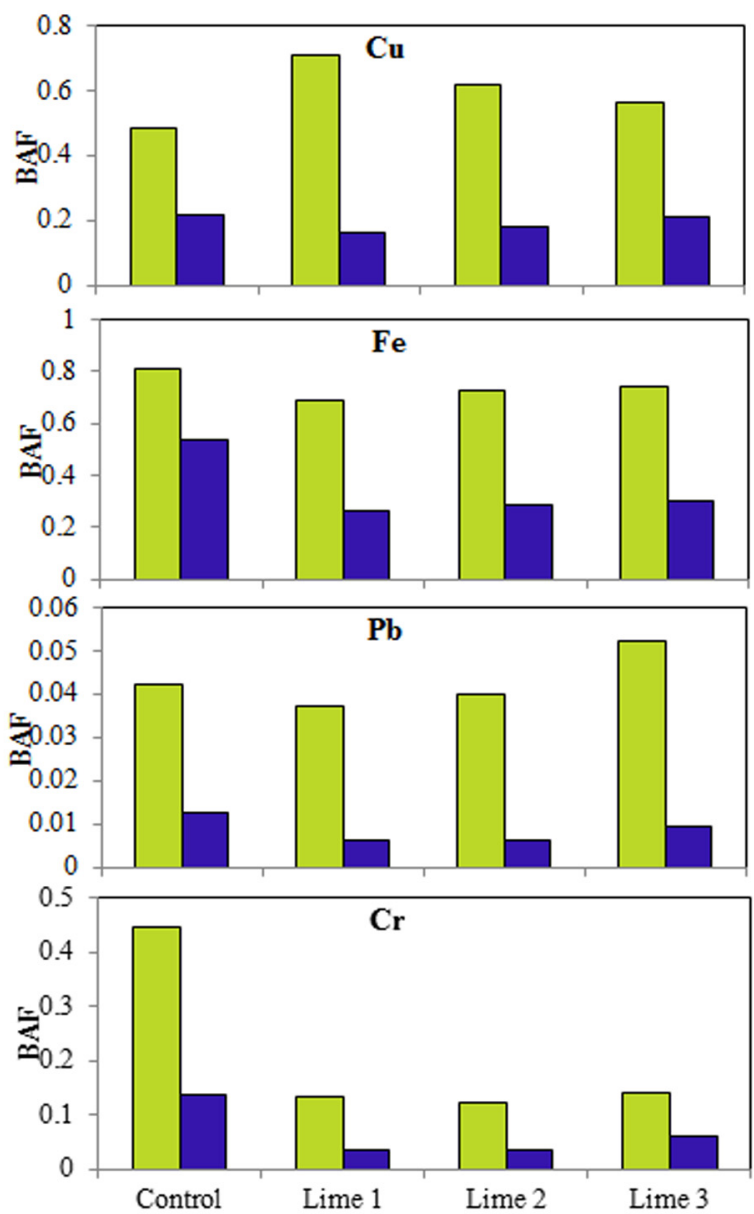

Fig. 3. Changes in bioavailability factor (BAF) of $\mathrm{Zn}, \mathrm{Cu}, \mathrm{Mn}, \mathrm{Fe}, \mathrm{Ni}, \mathrm{Pb}, \mathrm{Cd}$ and $\mathrm{Cr}$ in control, and lime treatments 1,2 , and $3 \mathrm{during}$ the rotary drum composting process. 
$\mathrm{M}$ represent as individual metals and $\mathrm{S}$ represented as sulfides.

In the composting process, microorganisms played a strong role in the degradation of organic matter and it into humic substances. Humic substances are naturally occurring complexing agents, so that binding of metal ions by humic substances is one of the most important environmental qualities of humic substances [4]. They have a large $\mathrm{pH}$-dependent charge and little permanent negative charge. They contain complex compositions with many active functional groups such as carboxyl and phenolic groups which become dissociated at high $\mathrm{pH}$ due to a decrease in intra and inter molecular hydrogen bonds and an increase in repulsive forces between the dissociated functional groups [28]. The OH-groups are responsible for the high sorption capacity of available fractions of metal ions. HMs form complexes with humic substances at the final stage of the composting process [26]. The binding of HMs with humic substances possibly occurs as chelation between a carboxyl group and a phenolic hydroxyl group, as chelation between two carboxyl groups, or as complexation with a carboxyl groups, as shown in Eq. (9).
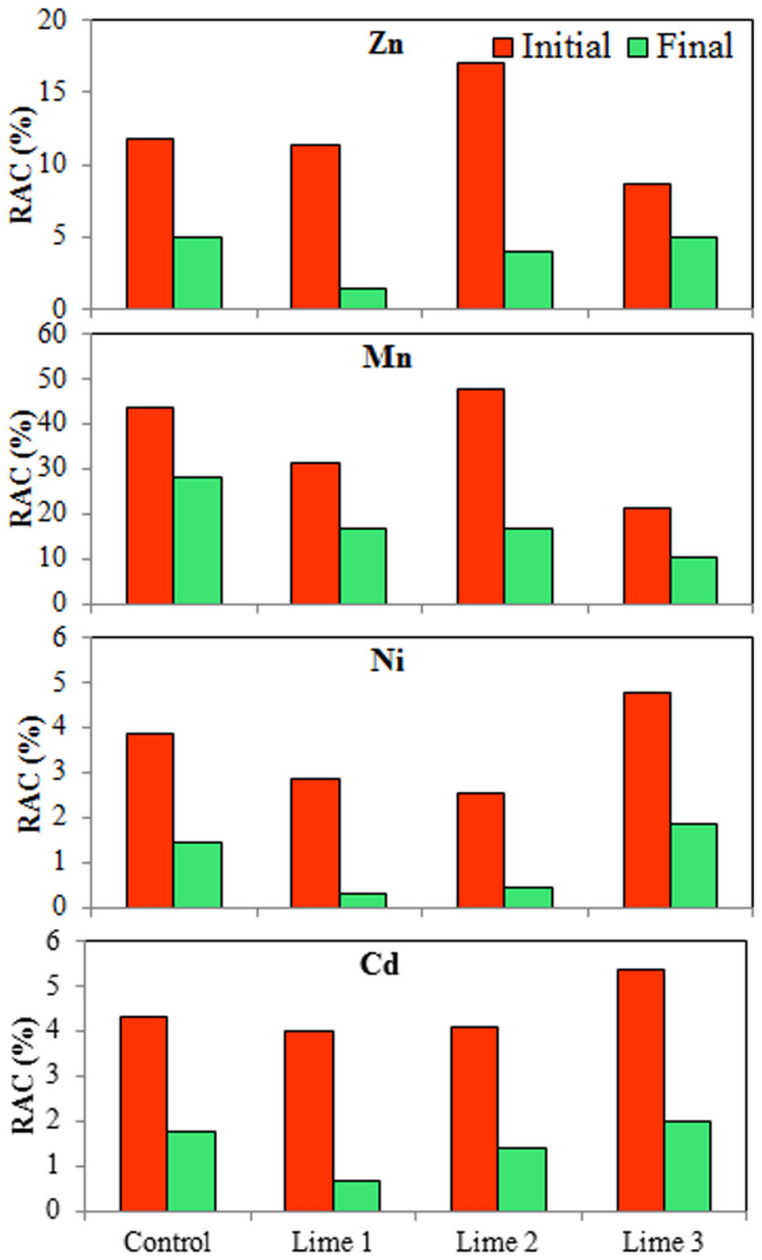

Fig. 4. Changes in risk assessment factor (RAC) of $\mathrm{Zn}, \mathrm{Cu}, \mathrm{Mn}, \mathrm{Fe}, \mathrm{Ni}, \mathrm{Pb}, \mathrm{Cd}$ and $\mathrm{Cr}$ in control, and lime treatments 1,2 , and 3 during the rotary drum composting process.

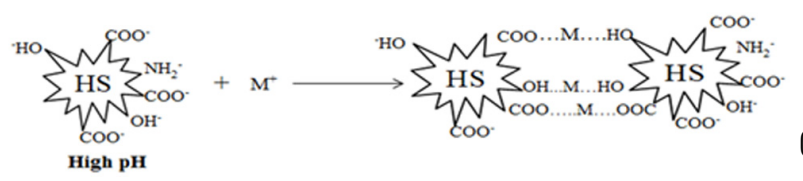

(b) Lime is an supplement that enhances the composting process by buffering against the decrease in $\mathrm{pH}$, providing better moisture holding capacity of materials, providing an appropriate amount of $\mathrm{Ca}$ to the composting microorganisms, and neutralizing the organic acids released during the composting process [16]. Therefore, lime amendment was very efficient in reducing the bioavailable fractions of HMs by forming less soluble carbonate salts during the rotary drum composting of water hyacinth mixed with waste lime [29]. Calcium hydroxide breaks into calcium ions and hydroxide ions in the presence of water and this is expressed in Eq. (10) [30]. Hydroxide ion combined with metal ion (M2+) forms metal hydroxides, as stated in Eq. (11). These metal hydroxides might be adsorbed on charged colloids such as degraded organic matter, consequently reducing the HM bioavailability [31].
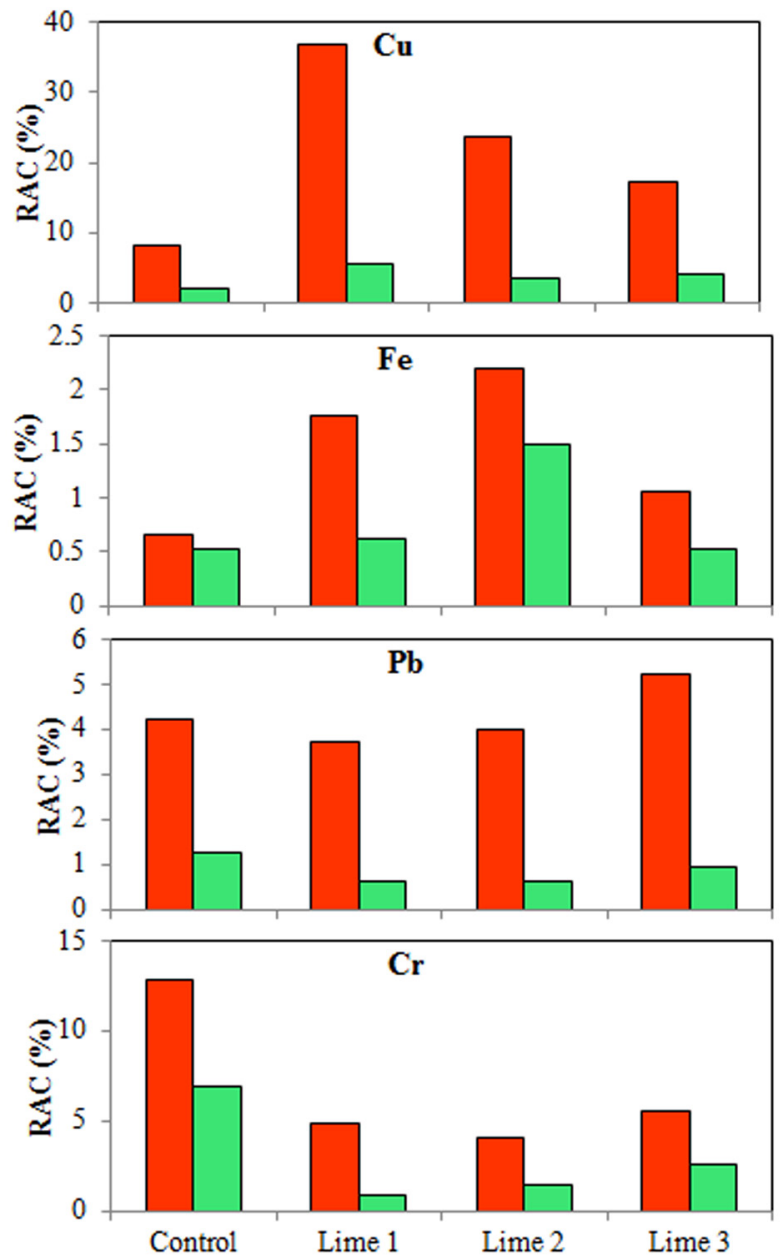
Table 7. A Comparative Study on the Reduction of Bioavailability Factors (BAF) of HMs during Water Hyacinth Composting [3, 8, 9]

\begin{tabular}{ccccc}
\hline \multirow{2}{*}{ HMs } & \multicolumn{4}{c}{ Maximum reduction of BAF (\%) } \\
\cline { 2 - 5 } & Agitated pile composting & Rotary drum composting & Agitated pile composting with lime & Present study \\
\hline $\mathrm{Zn}$ & 36.4 & 37.5 & 43.4 & 46.9 \\
$\mathrm{Cu}$ & 55.5 & 58.7 & 62.1 & 77.0 \\
$\mathrm{Mn}$ & 27.2 & 29.6 & 27.2 & 35.8 \\
$\mathrm{Fe}$ & 18.8 & 32.2 & 64.4 & 73.6 \\
$\mathrm{Ni}$ & 46.9 & 65.0 & 71.9 & 89.3 \\
$\mathrm{~Pb}$ & 55.6 & 70.2 & 61.0 & 85.0 \\
$\mathrm{Cd}$ & 10.5 & 56.7 & 62.1 & 84.0 \\
$\mathrm{Cr}$ & 36.4 & 70.5 & 58.9 & 73.0 \\
\hline
\end{tabular}

$$
\begin{gathered}
\mathrm{Ca}(\mathrm{OH})_{2} \mathrm{Ca}^{2+}+2 \mathrm{OH} \\
\mathrm{M}^{2+}+2 \mathrm{OH} \longrightarrow \mathrm{M}(\mathrm{OH})_{2}
\end{gathered}
$$

\subsection{Recovery Rate of HMs}

The sum of the five fractions (EXCH, CARB, RED, OMB and RESI) was in good agreement with the total HM concentration with acceptable recoveries (90.7-99.7\%). This clearly shows that the sequential extraction method used in detecting the speciation of HMs in the compost of water hyacinth was exact and reliable. As shown in Tables 3, 4, 5 and 6, the error for recovery of HMs was less than $10 \%$ in all three treatments.

\subsection{Risk Assessment Code (RAC)}

Based on the results of Fig. 4, all the metals showed low risk in water hyacinth compost. The HM risk was greatly lowered in the final compost of lime treatments 1 and 2, especially for $\mathrm{Fe}, \mathrm{Ni}, \mathrm{Pb}, \mathrm{Cd}$ and $\mathrm{Cr}$, with their risk reduced from low to zero. The risk of $\mathrm{Zn}$ remained at a low level, though the RAC values sharply decreased from 11.8 to $5.0 \%, 11.4$ to $1.4 \%, 17.1$ to $4.0 \%$ and 12.3 to $4.9 \%$ in control, and lime treatments 1,2 and 3 , respectively. Similarly to $\mathrm{Zn}$, the risk of $\mathrm{Cu}$ also remained at a low level. However, the risk for Mn remained at a medium level. The decrease of RAC shows that the easily bioavailable HMs (EXCH and CARB) were mainly transformed into the relatively stable $\mathrm{HM}$ fractions (RED, OMB and RESI) after completing the composting process, which decreased the toxicity and environmental risk of HMs.

\subsection{Comparative Studies on HM Speciation}

Very limited information is available in the literature on the speciation of HMs during water hyacinth composting in agitated pile [8], rotary drum [3] and agitated pile with waste lime addition [9]. The few available studies reported no significant BAF reduction. However, in the present study, BAF was reduced greatly for almost all HMs (Table 7). The higher reduction of BAF was attributed to the reduction of bioavailable fractions of HMs by conversion into inert fraction (RESI fraction) in the rotary drum composting of water hyacinth mixed with waste lime. Nomeda et al. [32] con- cluded that the bioavailability of $\mathrm{Cu}, \mathrm{Cd}, \mathrm{Mn}, \mathrm{Pb}$ and $\mathrm{Zn}$ increased after sewage sludge composting in pile, where the bioavailability of these metals was reduced greatly in the present study.

\section{Conclusions}

The combined effects of waste lime and rotary drum on the immobilization of heavy metals (HMs) were highly efficient. The Bioavailability factor (BAF) of $\mathrm{Zn}, \mathrm{Mn}, \mathrm{Ni}, \mathrm{Pb}$ and $\mathrm{Cr}$ was reduced significantly in lime treatments 1 and 2 compared to that in control and lime treatment 3 . However, the BAF of $\mathrm{Cu}, \mathrm{Fe}$ and $\mathrm{Cd}$ was reduced in all three lime treatments as compared to that in control. The total concentration of $\mathrm{Ni}$ was higher than that of $\mathrm{Zn}, \mathrm{Cu}$, Cd and Cr, but its BAF was the lowest among these metals. Therefore, these study results demonstrated the promising potential of the addition of waste lime for reducing the toxicity of HMs during the rotary drum composting of water hyacinth. Most of the eight toxic metals examined, such as $\mathrm{Ni}, \mathrm{Pb}, \mathrm{Cd}$ and $\mathrm{Cr}$, were mainly converted into their inert fraction (RESI fraction) due to the combined effects of waste lime and rotary drum. Lime addition at $3 \%$ did not exhibit greater reduction in the bioavailable fractions of HMs. The bioavailability of HMs was reduced greatly in the rotary drum composting of water hyacinth mixed with waste lime, cattle manure and sawdust. These study results have demonstrated the feasibility of applying waste lime to the immobilization of HMs under all favorable conditions for the composting process. Except for Mn, all selected HMs were reduced to the low or zero risk categories after the application of waste lime.

\section{Acknowledgements}

The authors gratefully acknowledge the financial support of the Department of Science and Technology (DST), Government of India. This research work was also partially supported by the Research Grant of Kwangwoon University in 2015.

\section{References}

1. Kalamdhad AS, YK Singh, Ali M, Khwairakpam M, Kazmi 
AA. Rotary drum composting of vegetable waste and tree leaves. Bioresour. Technol. 2009;100:6442-6450.

2. Gupta R, Mutiyar PK, Rawat NK, Saini MS, Garg VK. Development of a water hyacinth based vermireactor using an epigeic earthworm. Eisenia. fetida. Bioresour. Technol. 2007;98:2605-2610.

3. Singh J, Kalamdhad AS. Effect of rotary drum on speciation of heavy metals during water hyacinth composting. Environ. Eng. Res. 2013a;18:177-189.

4. Singh J, Kalamdhad AS. Assessment of bioavailability and leachability of heavy metals during rotary drum composting of green waste (Water hyacinth). Ecol. Eng. 2013b;52: 59-69.

5. Nair A, Juwarkar AA, Devotta S. Study of speciation of metals in an industrial sludge and evaluation of metal chelators for their removal. J. Hazard. Mater. 2008;152:545-553.

6. Wang X, Chen L, Xia S, Zhao J. Changes of $\mathrm{Cu}, \mathrm{Zn}$ and $\mathrm{Ni}$ chemical speciation in sewage sludge co-composted with sodium sulfide and lime. J. Environ. Sci. 2008;20:156-160.

7. Central Pollution Control Board (CPCB). Assessment of utilization of industrial solid wastes in cement manufacturing. New Delhi: MoEF; 2006.

8. Singh J, Kalamdhad AS. Concentration and speciation of heavy metals during water hyacinth composting. Bioresour. Technol. 2012;124:169-179.

9. Singh J, Kalamdhad AS. Effect of lime on speciation of heavy metals during agitated pile composting of water hyacinth. Front. Environ. Sci. Eng. 2014;(In press).

10. Tessier A, Campbell PGC, Bisson M. Sequential extraction procedures for the speciation of particulate trace metals. Anal. Chem. 1979;51:844-851.

11. Singh J, Kalamdhad AS. Effect of Eisenia fetida on speciation of heavy metals during vermicomposting of water hyacinth. Ecol. Eng. 2013c;60:214-223.

12. Sundaray SK, Nayak BB, Lin S, Bhatta D. Geochemical speciation and risk assessment of heavy metals in the river estuarine sediments-a case study: Mahanadi Basin, India. J. Hazard. Mater. 2011;186:1837-1846.

13. Yuan X, Huang H, Zeng G, et al. Total concentrations and chemical speciation of heavy metals in liquefaction residues of sewage sludge. Bioresour. Technol. 2011;102:4104-4110.

14. Jiang T, Schuchardt F, Li G, Guo R, Zhao Y. Effect of C/N ratio, aeration rate and moisture content on ammonia and greenhouse gas emission during the composting. J. Environ. Sci. 2011;23:1754-1760.

15. Wong JWC, Selvam A. Speciation of heavy metals during co-composting of sewage sludge with lime. Chemosphere 2006;63:980-986.

16. Chiang KY, HuangHJ, Chang CN. Enhancement of heavy metal stabilization by different amendments during sewage sludge composting process. J. Environ. Eng. Manage. 2007;17:249-256.

17. Zheng GD, Chen TB, Gao D, Luo W. Stabilization of nickel and chromium in sewage sludge during aerobic composting. J. Hazard. Mater. 2007;142:216-221.

18. Liu Y, Ma L, Li Y, Zheng L. Evolution of heavy metal speciation during the aerobic composting process of sewage sludge. Chemosphere 2007;67:1025-1032.

19. Zhu R, Wu, M, Yang J. Mobilities and leachabilities of heavy metals in sludge with humus soil. J. Environ. Sci. 2011;23: 247-254.

20. Kumpiene J, Lagerkvist A, Maurice C. Stabilization of As, Cr, $\mathrm{Cu}, \mathrm{Pb}$ and $\mathrm{Zn}$ in soil using amendments - A review. Waste Manage. 2008;28:215-225.

21. Smith SR. A critical review of the bioavailability and impacts of heavy metals in municipal solid waste composts compared to sewage sludge. Environ. Int. 2009;35:142-156.

22. Su DC, Wong JWC. Chemical speciation and phytoavailability of $\mathrm{Zn}, \mathrm{Cu}, \mathrm{Ni}$ and $\mathrm{Cd}$ in soil amended with fly ash-stabilized sewage sludge. Environ. Int. 2003;35:142-156.

23. Qiao L, Ho G. The effects of clay amendment and composting on metal speciation in digested sludge. Water Res. 199;31: 951-964.

24. Haroun M, Idris A, Omar SRS. A study of heavy metals and their fate in the composting of tannery sludge. Waste Manage. 2007;27:1541-1550.

25. Singh J, Kalamdhad AS. Effects of lime on bioavailability and leachability of heavy metals during agitated pile composting of water hyacinth. Bioresour. Technol. 2013d;138:148-155.

26. Cai QY, Mo C, Wu QT, Zeng QY, Katsoyiannis A. Concentration and speciation of heavy metals in six different sewage sludge-composts. J. Hazard. Mater. 2007;147:1063-1072.

27. Min XB, Xie XD, Chailly LY, Liang YJ, Li MI, Yong KE. Environmental availability and ecological risk assessment of heavy metals in zinc leaching residue. Trans. Nonferrous. Metals. Soc. China. 2013;23:208-218.

28. Gungor EBO, Bekbolet M. Zinc release by humic and fulvic acid as influenced by $\mathrm{pH}$, complexation and DOC sorption. Geoderma 2010;159:131-138.

29. Fang M, Wong JWC. Effects of lime amendment on availability of heavy metals and maturation in sewage sludge composting. Environ. Pollut. 1999;106:83-89.

30. Montes-Hernandez G, Concha-Lozano N, Renard F, Quirico E. Removal of oxyanions from synthetic wastewater via carbonation process of calcium hydroxide: Applied and fundamental aspects. J. Hazard. Mater. 2009;166:788-795.

31. Garau G, Castaldi P, Santona L, Deiana P, Melis P. Influence of red mud, zeolite and lime on heavy metal immobilization, culturable heterotrophic microbial populations and enzyme activities in a contaminated soil. Geoderma 2007;142:47-57.

32. Nomeda S, Valdas P, Chen SY, Lin JG. Variations of metal distribution in sewage sludge composting. Waste Manage. 2008;28:1637-1644. 